\title{
TECNOLOGIAS INTEGRADAS À SALA DE AULA DIÁLOGOS COM AS TEORIAS DE APRENDIZAGEM
}

\section{ARTIGO ORIGINAL}

MARTINS, Geisse ${ }^{1}$

MARTINS, Geisse. Tecnologias integradas à sala de aula diálogos com as teorias de aprendizagem. Revista Científica Multidisciplinar Núcleo do Conhecimento. Ano 05, Ed. 09, Vol. 02, pp. 21-29. Setembro de 2020. ISSN: 2448-0959, Link de acesso: https://www.nucleodoconhecimento.com.br/educacao/tecnologias-integradas

\section{RESUMO}

Este trabalho tem como objetivo tentar compreender como os princípios tecnológicos e pedagógicos, para o uso de tecnologias na sala de aula, dialogam com as teorias de aprendizagem existentes. Diante aos desafios propostos pelo impacto nos comportamentos, usos, costumes e, sobretudo, nos processos do ensino e aprendizagem na contemporaneidade. Cujas as dimensões estão alicerçadas pelo uso de novas tecnologias. Um dos grandes desafios da educação contemporânea é ser capaz de aplicar as principais teorias da educação nas práticas que são mediatizadas pelo uso de novas tecnologias da informação e também tecnologias que estimulam o conhecimento. Essas práticas não podem estar dissociadas de uma realidade que cada vez mais preconiza o ensinar e praticar a ética, bons costumes e até desestimular o ódio e a violência cibernética hoje presente inclusive dentro das instituições escolares. Diante de um cenário que muda de forma alucinante é possível perceber que há um choque de geração e esse confronto via de regra acontece em virtude do "modus operandi" das gerações e de como lidam com a tecnologia e aplicação desta nos processos de ensino e aprendizagem. Estando à luz das principais teorias da aprendizagem sejam elas do passado ou do presente, servem para nortear a aplicação e o uso de tecnologias na aprendizagem. Como metodologia

\footnotetext{
${ }^{1}$ Mestrando em Tecnologias Emergentes em Educação Must University.
} 
para elaboração deste trabalho foi utilizada a análise bibliográfica dos principais teóricos da educação. Para tanto, foi necessário, buscar em livros, nas perspectivas e nas análises de autores que versam sobre as teorias de aprendizagem bem como a tecnologia interfere no modo de vida e, consequentemente, estabelece novos paradigmas. Tendo como conclusão tentar compreender como as teorias de aprendizagem podem ser compreendidas e de forma podem ser aplicadas na realidade contemporânea da educação cada vez mais substanciada pelo uso de novas tecnologias. Ambientes de aprendizagem que cada vez estão sujeitos a mudanças constantes e utilizam-se cada vez mais de tecnologias, também estão cada vez mais aplicando teorias de aprendizagem em suas práticas escolares.

Palavras chave: Educação, tecnologias, adaptava, multimídia.

\section{INTRODUÇÃO}

Fato é que, nos últimos anos, a tecnologia vem mudando a forma de se comunicar e, também, de se aprender. Com efeito, tudo isso tem um impacto considerável nos ambientes de aprendizagem e, diretamente, na sala de aula.

Todos esses elementos, entrelaçados numa cultura digital, reformulam a maneira de se comunicar, entreter, transacionar e de se aprender na sociedade do conhecimento. Novos elementos tecnológicos e o crescimento exponencial da informação e do conhecimento impactam a educação do século XXI. Esses impactos, não acontecem somente no "modus operandi", mas, além disso, impactos de ordem comportamental e atitudinal.

Dentro deste universo de descobertas e avanços tecnológicos da comunicação e da informação, inúmeras teorias surgiram e ainda surgem, para tentar compreender de onde vem o conhecimento e como ele se transforma. Para tanto, grandes teorias como behaviorismo, cognitivismo, construtivismo e, muito recentemente, o conectivismo, através de seus pensadores, buscam compreender essas questões. 
Esse trabalho tem como objetivo tentar compreender como os princípios tecnológicos e pedagógicos, para o uso de tecnologias na sala de aula, dialogam com as teorias de aprendizagem existentes, frente aos desafios propostos pelo impacto nos comportamentos, usos, costumes e, sobretudo, nos processos do ensino e aprendizagem.

\section{DESENVOLVIMENTO}

Desde o início dos tempos, a curiosidade e a vontade de saber moveram a humanidade e impulsionaram a espécie humana, em sua trajetória de desenvolvimento e evolução, até os dias atuais. Passamos a manifestar conquistas, desafios, comportamentos e rituais expressos em desenhos nas paredes das cavernas. Com o uso de símbolos e da escrita, das tábuas de argila e da escrita cuneiforme, do antigo Egito, tudo isso influenciou o surgimento de civilizações como a Grécia e Roma, mais adiante, com o advento do papel e a invenção da prensa de Gutenberg, que impulsionou as artes, a ciência, a literatura, através da escrita, e, também, a produção e a difusão do conhecimento através dos livros impressos.

Segundo a inteligência de Lucci (2000, p.5)

[...] Essa nova sociedade, que está se formando, e que tem por base o capital humano ou intelectual, é chamada de Sociedade do Conhecimento. Nessa sociedade onde as ideias, portanto, passam a ter grande importância, estão surgindo, em várias partes do mundo, os Think Thanks, que nada mais são do que grupos ou centros de pensamentos para a discussão de ideias. Esses centros têm por objetivo a construção de um mundo, de uma sociedade mais saudável, do ponto de vista econômico e social, que possa desfrutar de uma melhor qualidade de vida. 


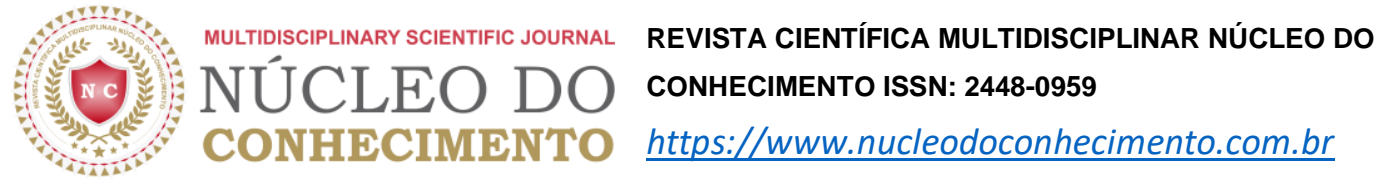

Figura 1 - Educação no Antigo Egito

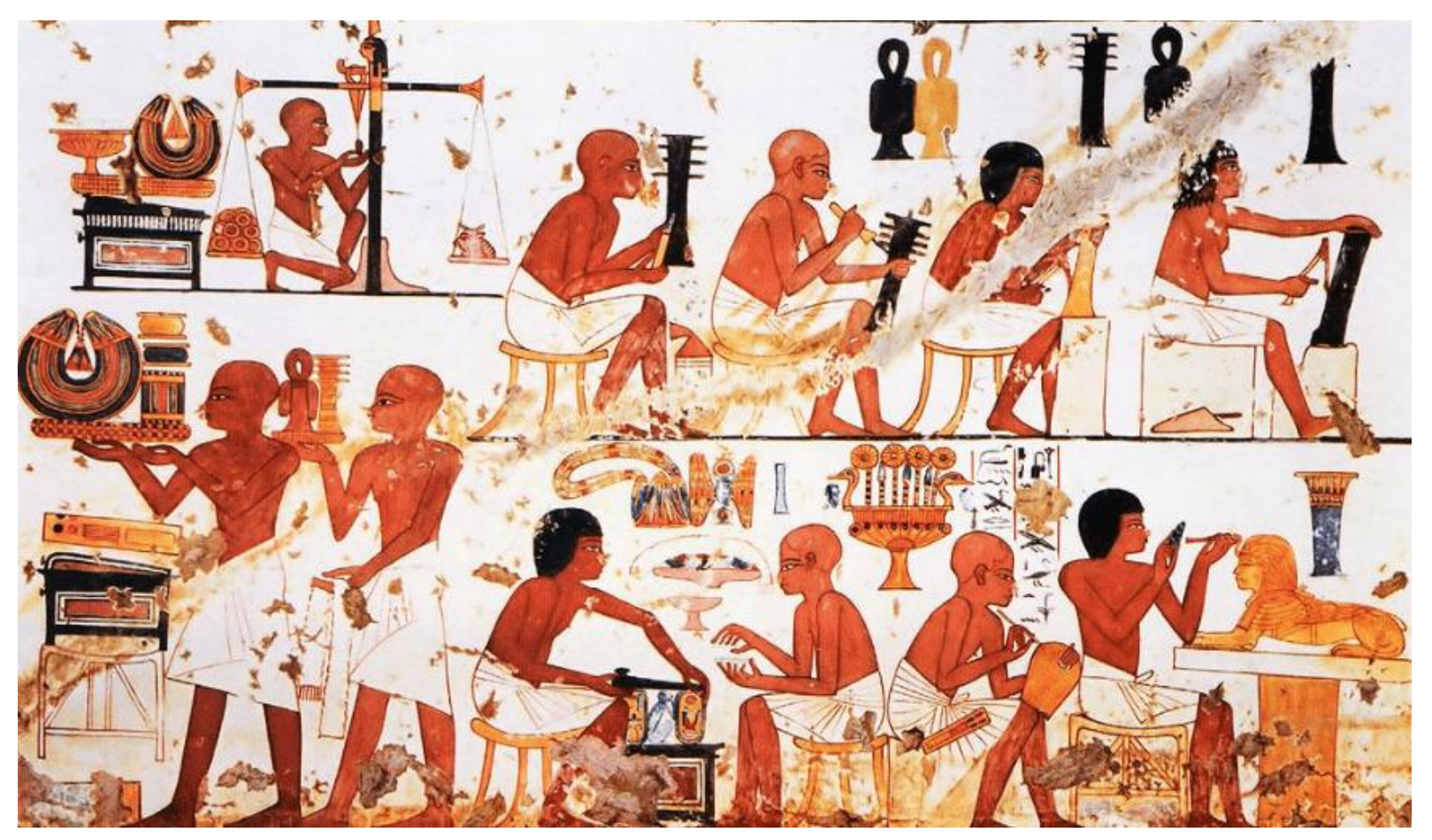

Fonte: Google imagens

Figura 2 - Escola no Brasil - Uso de Tecnologia Ensino Fundamental

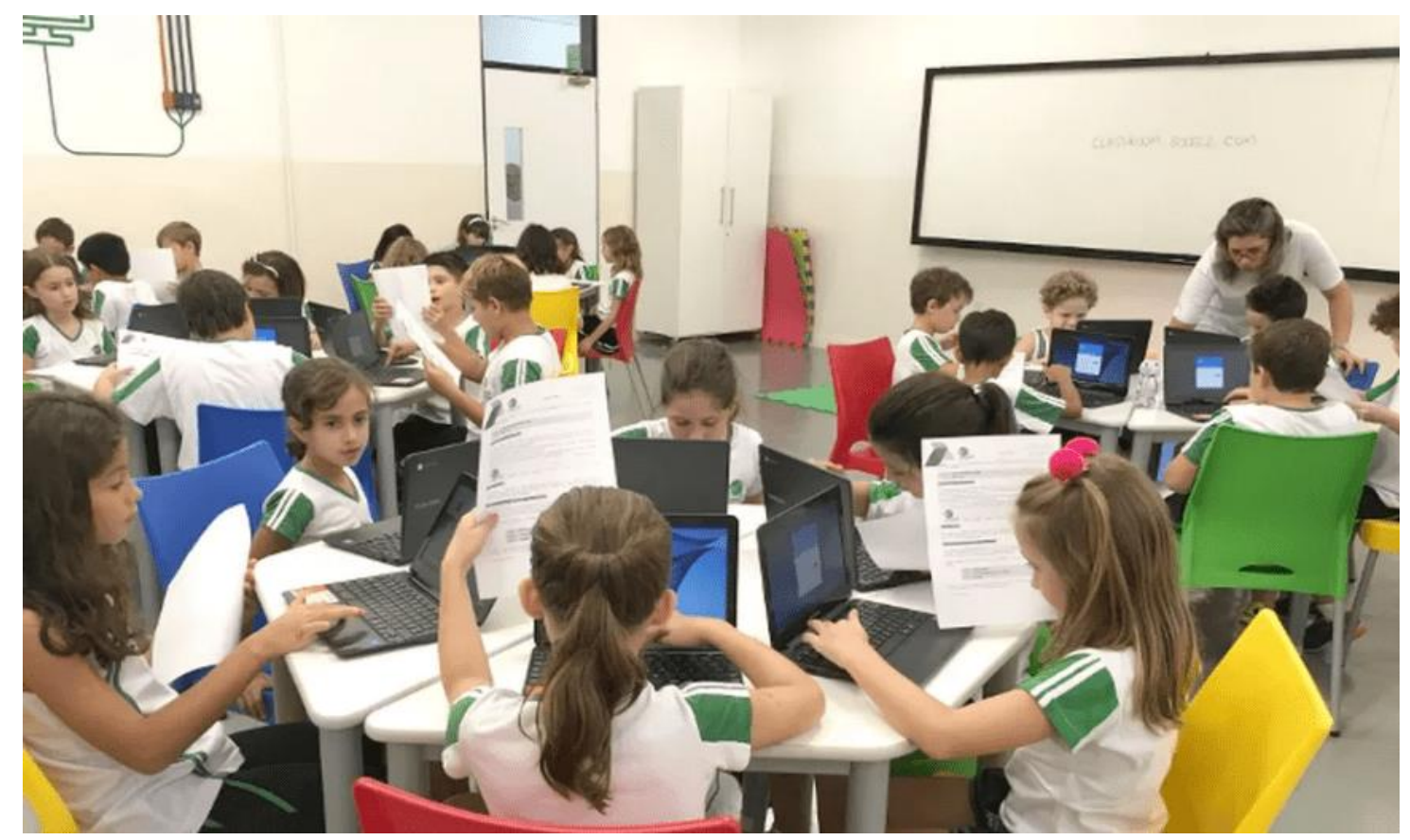

Fonte: Imagens do acervo do autor

$\mathrm{RC}: 58493$

Disponível em: https://www.nucleodoconhecimento.com.br/educacao/tecnologias-integradas 
Mais recentemente, como advento das tecnologias da comunicação e da informação (TICs), impactou, consideravelmente, a maneira como as pessoas se comunicam e, também, como aprendem. A velocidade de produção e propagação de informação e conhecimento é cada vez mais curta e se propaga por diversos meios e mídias. Toda essa dinâmica e transformação nos diversos processos, também, influenciam, diretamente, no comportamento das pessoas, frente ao uso de tecnologias.

Questões éticas, comportamentais e de ordem de convívio social tais como:

- Assédios (sexual, virtual, escolar);

- Segurança digital;

- Cidadania digital e;

- Direitos e responsabilidades,

Todas essas questões permeiam a chamada sociedade da informação e, agora, do conhecimento, sociedade subdividida em inúmeras subclasses que criam novas possibilidades, para os setores econômicos, político, cultural e social. Diante de todo esse cenário, em que se instala uma assimetria entre o uso das tecnologias e dos princípios e valores humanos. Diante desse cenário, faz-se necessário evocar as principais teorias de aprendizagens, existentes, que possam estabelecer um diálogo com os princípios tecnológicos e pedagógicos, para o uso de tecnologias na sala de aula, não somente, para potencializar o conhecimento, mas, também, para permitir um enfrentamento de questões, tão amplas e complexas, e que fazem parte de todo esse contexto.

As teorias de aprendizagem, que se apoiam na cognição, no comportamento e na construção do conhecimento (via de regra fundamentadas numa tradição epistemológica) possuem sua ótica alicerçada em pensadores que tentam explicar como o ser humano constrói o conhecimento e as suas dinâmicas, entrelaçadas no comportamento humano.

Para Imbérnom (2010, p.36): 
Para que o uso das TIC signifique uma transformação educativa que se transforme em melhora, muitas coisas terão que mudar. Muitas estão nas mãos dos próprios professores, que terão que redesenhar seu papel e sua responsabilidade na escola atual. Mas outras tantas escapam de seu controle e se inscrevem na esfera da direção da escola, da administração e da própria sociedade.

Na mesma direção e sentido Lévy (1993) nos oferece a seguinte afirmação:" [...] as novas tecnologias, utilizadas como ferramentas pedagógicas nas escolas, redefinem a função docente, pois, agregam às práticas de ensino e aprendizagem, novos modos de acesso aos conhecimentos".

Sendo o ser humano, um ser social, não está imune ao que the acontece ao seu entorno. Vygotsky (1991) é enfático nas suas considerações sobre como ocorre a aprendizagem e afirma que o interacionismo é o ponto e força axial no que se refere ao processo de aprender das pessoas. Por conseguinte, quando se trata de interação social, mediada por uso de tecnologias dentro da sala de aula, pontos centrais, como respeito entre pessoas e suas singularidades, são determinantes para uma construção salutar nos processos do ensino e da aprendizagem.

Ainda na mesma linha de raciocínio Ivic (2010, p. 19) afirma:

Analisando o papel da cultura no desenvolvimento individual, Vygotsky desenvolve duas ideias análogas. No conjunto das aquisições da cultura, centraliza sua análise sobre aquelas que são destinadas a comandar os processos mentais e o comportamento do homem. São os diferentes instrumentos e técnicas (incluindo as tecnologias) que o homem assimila e orienta para si mesmo, para influenciar suas próprias funções mentais. Assim, cria-se um sistema gigantesco de "estímulos artificiais e externos" pelos quais o homem domina seus próprios estados interiores.

Nas relações sociais e histórico-culturais, as questões de ordem psicológicas são o pilar de apoio e, também, se justapõem com a cultura que é a parte fundamental no processo da construção humana que, não raro, acontece, também, nos ambientes de aprendizagem, sejam eles físicos ou virtuais. Como bem preconizou Piaget (1978) nas suas afirmações sobre equilibração majorante (nos conceitos de assimilação, acomodação e desequilibração), com efeito, o uso de novas tecnologias nos processos de ensinar e aprender podem colaborar para que se possa existir um 
constante e cíclico desequilíbrios, uma vez que se utiliza outras fontes e formas de aprender ( uso de tecnologias adaptativas, ensino híbrido, sala de aula invertida, uso de vídeos e plataformas de colaboração).

Importante ressaltar que, aprender tem a ver, também, com mudança de comportamento e ajustamento social. Há de se atentar que, em salas de aula que utilizam tecnologia e que pessoas hiperconectadas precisam ter em mente, que não basta apenas conteúdos em mídias interessantes ou mesmo com dispositivos ultramodernos, como a realidade aumentada ou a realidade virtual, mas, sobretudo, com o processo atual de aprendizagem e com os valores e princípios que norteiam a sociedade.

Gardner (2006) e sua teoria das Inteligências Múltiplas pode ser evocada e suas ideias colocam-se em marcha no sentido de consubstanciar que o elemento essencial em ambientes de aprendizagem é uma participação ativa (dos seus agentes) e a troca de experiências (teóricas e empíricas) mediadas pelo diálogo e com interação dialógica/dialética que privilegie o intercâmbio de novas ideias, mas, sobretudo, em impelir o desenvolvimento da cognição, bem como, também, melhoria nas relações interpessoais, inclusive as que são mediatizadas por uso de tecnologias.

As proposições do professor de Harvard harmonizam-se com as novas formas de aprender e ensinar, que acontecem dentro das atuais salas de aula, que se beneficiam com a aprendizagem mediatizada por uso de tecnologias.

Mais recentemente, os pensadores da linha do conectivismo vêm lançando luz em áreas de sombra, no tocante à aprendizagem, uma vez que todos esses novos elementos tecnológicos e suas implicações não estavam ao alcance e radar das teorias do behaviorismo, cognitivismo e construtivismo.

De acordo a teoria conectivista, na aprendizagem em sala de aula, mediatizada por uso de tecnologias há integração entre os atores participantes e que estes estão imersos em princípios explorados pelo caos, redes de relacionamentos (ativas e passivas) e com alto grau de complexidade e auto-organização, e que essas 
nebulosas de elementos estão em constantes movimentos de mudança e com, até, descontrole dos limites do raio de ação na construção do conhecimento. Em suma, tudo muda constantemente e é de difícil controle.

Na perspectiva de Siemens (2004, p.3)

As teorias da aprendizagem estão preocupadas com o processo atual de aprendizagem, não com o valor do que está sendo aprendido. Em um mundo ligado em rede, a espécie exata de informação que adquirimos é explorando a sua importância. A necessidade de avaliar a importância de aprender alguma coisa é uma meta-habilidade que é aplicada antes da própria aprendizagem começar. Quando o conhecimento é sujeito à parcimônia, o processo de avaliar a importância é assumido como intrínseco à aprendizagem. Quando o conhecimento é abundante, a avaliação rápida do conhecimento é importante. Preocupações adicionais surgem do rápido aumento da informação. Nos ambientes atuais, frequentemente, a ação é necessária sem aprendizagem pessoal - isto é, é preciso agir buscando informações fora do nosso conhecimento primário. A habilidade de sintetizar e reconhecer conexões e padrões é uma habilidade valiosa.

Não obstante, deste caudaloso caos, que possa sugerir uma anarquia digital, compreender que novas informações estão sendo continuamente produzidas, compartilhadas e, como consequência, novos conhecimentos em sua gênese podem surgir, é vital ensinar a habilidade de distinguir entre o que é importante e o que não é. O que se pode fazer e o que não se pode fazer, as balizas mestres da ética, dos bons costumes, da moral, estabelecida em sociedade, precisam estar sempre no cerne de todo e qual processo de aprendizagem, e, mais ainda, em salas de aula, tudo isso precisa ser explicitado e amplamente investigado pelos alunos e alunas.

Em sintonia com as proposições de Siemens e suas teorias do conectivismo, a pedagogia contemporânea tem agora, por horizonte, analisar estratégias de ensino e aprendizagem que privilegiam a autoria e a colaboração em rede.

Em salas de aula, que se utilizam de tecnologias, é imprescindível que todos os envolvidos compreendam que a aprendizagem e a construção de conhecimentos se apoiam na diversidade de opiniões e que atos de assédio, exclusão e, até mesmo, crimes cibernéticos não contribuem em nada para a sociedade. 
Ao se apropriar dos princípios do conectivismo, as práticas pedagógicas, sempre que possível, poderão amadurecer conceitos e propor mudanças de comportamento, pois, mais do que nunca, faz-se necessário cultivar e manter conexões para facilitar a aprendizagem contínua, ancorada no respeito e em total harmonia com a cidadania digital.

\section{CONCLUSÃO}

O ritmo alucinante em que o uso de novas tecnologias causa na sociedade é um fato. Em ambientes de aprendizagem isso ocorre de forma ainda mais acelerada e requer a adoção de novas estratégias pedagógicas frente aos novos desafios que surgem com o advento e o uso de novas tecnologias.

Sendo a escola, um extrato da sociedade que também vivencia toda e qualquer mudança, frequentemente, é o local de maior difusão da informação, arte, cultura e profusão do conhecimento. Com efeito, a aplicação de tecnologias em salas de aula, também, convida a pedagogia a estabelecer e estruturar acompanhamento, para que questões relacionadas com cidadania digital, segurança digital e responsabilidades façam parte e estejam presentes diante deste novo cenário que é passível de mudança em todo o instante.

Não obstante, possa parecer que as teorias de aprendizagem estejam desconexas com esse momento atual dentro das salas de aula, em que o uso e as aprendizagens acontecem mediatizadas pelas tecnologias, ao contrário as abordagens e análises das teorias não são estéreis, possuem total aderência para contribuir para elevar o nível de entendimento e efusiva participação de todos os atores envolvidos com a educação contemporânea.

Por conseguinte, as teorias de aprendizagem não somente são evocadas, para trazerem um melhor entendimento, mas, sobretudo, para poderem ancorar as decisões de planeamento pedagógico e de novas estratégias de ensino e aprendizagem, frente aos princípios tecnológicos, já instalados, operantes nas salas 
de aulas, e que, de certa maneira, provocam alterações no comportamento, na cultura e no social.

Novas abordagens teóricas, como o conectivismo, trazem novas proposições, uma vez que, a tecnologia é a força axial que tenciona todas as variáveis, nesse cenário de mutações alucinantes, bem como, têm uma influência sobre os atores envolvidos em educação, cujas práticas são mediatizadas pelo uso das TICs.

E por fim, não basta apenas ensinar sobre a tecnologia e com a tecnologia, imperativamente, nos dias atuais, é mais, que necessário, educar para a cidadania digital, para que se possa extrair o máximo que a tecnologia proporcione, ao mesmo tempo que se possa construir uma sociedade mais justa, mais humana e fraterna, com o uso que o conhecimento impulsiona a humanidade.

\section{REFERÊNCIAS}

HOWARD.G. Multiple intelligences: New Horizons. New York: Basic Books.2006 IMBERNÓN, F. Formação docente e profissional: formar-se para a mudança e a incerteza. 7. Ed. São Paulo: Cortez, 2010.

IVIC. Edgar P.C. Lev Semionovich Vygotsky. Fundação Joaquim Nabuco, Editora Massangana.Recife.2010.

LEVY. P. As tecnologias da inteligência: o futuro do pensamento na era da informática. Rio de Janeiro. 1993

LUCCI.E. A. A era pós-industrial, a sociedade do conhecimento e a educação para o pensar. Editora Saraiva. 2000

PIAGET. J. Epistemologia genética. 2. ed. São Paulo: Abril Cultural, Coleção Os Pensadores, 1978.

SIEMENS.G. Conectivismo: Uma teoria de Aprendizagem para a idade digital. 2004. 
VIGOTSKY, L. S. Aprendizagem e desenvolvimento intelectual na idade escolar. In: LURIA, A. R. et al. Psicologia e pedagogia: Bases psicológicas da aprendizagem e do desenvolvimento. v.1 2. ed. Lisboa: Estampa, 1991.

Enviado: Abril, 2020.

Aprovado: Setembro, 2020. 